\title{
IMMUNE-ENZYMATIG BIOSENSORS BASED ON THE OXIDE CERIUM ISFETS: SOME PHYSICAL AND FUNCTIONAL CHARACTERISTICS AT THE DETERMINATION OF SIMAZINE AND T2-MYCOTOXIN
}

\author{
N.F. Starodub ${ }^{1,2}$, A. N. Shmiryeva $^{3}$ \\ ${ }^{1}$ National University of Life and Environmental Sciences, 15 Herojev Oboroni Str., Kiev, 03041 Ukraine; \\ nikstarodub@yahoo.com \\ ${ }^{2}$ T.Shevchenko Kiev National University, \\ ${ }^{3}$ Kiev National Technical University, "KPI", 37 Prospect Peremohy, Kyiv, 03056, Ukraine
}

Summery. Immune biosensor based on the CeOx was created and its analytical characteristics were studying at the determination in model solutions of mycotoxin T2 and herbicide simazine. It was shown that input and output characteristics of the IsFET's with the CeOx dielectric have the increasing of the $\mathrm{pH}$ sensitivity (about $58 \mathrm{mV} / \mathrm{pH}$ that was near to the maximal possible index $-59 \mathrm{mV} / \mathrm{pH}$ ) in the comparison with $\mathrm{Si}_{3} \mathrm{~N}_{4}$. It is due to high density of the surface sensitive centers (up to $10^{20} \mathrm{M}^{-2}$ ), large level of the permittivity $(\varepsilon=26)$ and the band-gap energy $(3.6 \mathrm{eV})$ of cerium. All these effects lead to decreasing of the current losses through the dielectric. Reliable decrease of the biosensor signal at the "competitive" way of analysis (labeled and native substances competed for binding with antibodies - Ab) was observed down to 1.0 and $3.0 \mathrm{ng} \mathrm{ml}^{-1}$ of simazine and T2 mycotoxin, accordingly. The linearity of signal decrease was observed in the range of T2 mycotoxin concentrations from 5 to $190 \mathrm{ng} \mathrm{ml}^{-1}$. The similar situation was occurred in case of simazine $\left(2-150 \mathrm{ng} \mathrm{m}^{-1}\right)$. The overall time of the assay including the duration of all preparation stages was $30 \mathrm{~min}$. In case of the analysis by "to saturated way" allowed reaching sensitivity $0.5 \mathrm{ng} \mathrm{ml}^{-1}$ and linearity in the range $1.0-200 \mathrm{ng} \mathrm{m}^{-1}$ and $0.5-170$ for T2 mycotoxin and simazine, respectively. The overall time of the incubations was the same $10 \mathrm{~min}$ (5 min for the staying chip in the solution of the native and the labeled substances). There is necessary to note that the sensitivity and the stability of the biosensors based on the $\mathrm{Si}_{3} \mathrm{~N}_{4}$ and $\mathrm{CeOx}$ IsFETs are much better for last one.

Key words: cerium oxide, ISFETs, immune biosensor, mycotoxin, simazine, control.

Introduction. One of the main tasks today is the control of the content of toxic substances including pharmaceutical products in environmental objects, living organisms and during some technological process. Modern physical chemical methods (chromatography, mass spectroscopy and nuclear magnetic resonance) in spite of their perfection with regard to sensitivity and specificity can not give a very fast response about the presence of concrete substance in sample to be analysed. Biosensors may serve in this respect as the powerful tools. Taken into attention many of preliminary investigations and functional principles of ion-selective field effect transistors (ISFETs) have every reason to believe that a new generation of biosensors based on them will be widely used practically to solve the problems mentioned above.

As a rule in modern ISFETs $\mathrm{SiO}_{2}, \mathrm{Si}_{3} \mathrm{~N}_{4}, \mathrm{Ta}_{2} \mathrm{O}_{5}$ are used as sensitive layer of insulator. Unfortunately, this type of ISFETs is characterized by insufficient sensitivity in the comparison with the glass ionsensitive electrodes. It may be connected with the existing charge states in oxide and at the interface of oxide and semiconductor which are responsible for the non stability and drift of characteristics [1]. The obtaining of qualitative oxides having a small concentration of surface states (Nss=up to $10^{10} \mathrm{~cm}^{-2} \mathrm{eV}^{-1}$ ) and trace quantity of mobile charges connected with a big engineering difficulties. In addition, the $\mathrm{SiO}_{2}$ surface has a relatively small concentration of ion-sensitive centers (about $10^{13} \mathrm{~cm}^{-2}$ ). $\mathrm{Si}_{3} \mathrm{~N}_{4}$ has number advantages in the comparison with $\mathrm{SiO}_{2}$ : higher electrical strength, chemical stability in acid-alkali mediums, tightness for the mobile sodium ions and higher density of surface-sensitive centers (up to $10^{15}$ $\mathrm{cm}^{-2}$ ), which leads to high $\mathrm{pH}$ sensitivity. The high density of surface state on the silicon is the main disadvantage of $\mathrm{Si}_{3} \mathrm{~N}_{4}$. However, when using a two-layer dielectric $\mathrm{SiO}^{2}-\mathrm{Si}^{3} \mathrm{~N}^{4}$, which preserves the benefits of both materials, the instability of the structures is significantly reduced. $\mathrm{Ta}_{2} \mathrm{O}_{5}$ may be used as senssitive dielectric layer too. This material has a very high density of surface sites, resulting in high $\mathrm{pH}$ achieved sensitivity. However, it was shown that at the cathode polarization of semiconductor relative to the electrolyte in the voltage range $-1 \ldots-1.5 \mathrm{~V}$ there is a sharp increase in leakage currents through the insulator to the values of more than $100 \mathrm{nA}$. For comparison, it should be noted that in similar conditions, leakage currents for $\mathrm{SiO}_{2}$ is $50-100 \mathrm{nA}$ at voltages $-1 \ldots-2 \mathrm{~V}$, for a two-layer dielectric $\mathrm{SiO}_{2}-\mathrm{Si}_{3} \mathrm{~N}_{4}$ leakage 
currents do not exceed 5-15 nA [1], and leakage currents for $\mathrm{CeO}_{2} 10^{-12}-10^{-13} \mathrm{~A}$ at the same electric field. The last oxide has a number of advantages in the comparison with $\mathrm{SiO}_{2}$ and $\mathrm{Si}_{3} \mathrm{~N}_{4}$ : 1) high level of dielectric permeability $(\varepsilon=26)$ and, correspondingly, large electric strength that allows to use more thin dielectric layers; 2) the energy gap $\mathrm{Eg}=3,6 \mathrm{eV}$, which leads to a better dielectric isolation structure, and reduces leakage current through the dielectric: 3 ) chemical resistance in acid-alkaline environments and tightness for mobile ions sodium; 4) a higher density of surface-sensitive centres (up to $10^{16} \mathrm{~cm}^{-2}$ ), which leads to high $\mathrm{pH}$ sensitivity and the parameter mismatch in the lattice constants of $\mathrm{CeO}_{2}$ and silicon $(\Delta \alpha / \alpha=0,35 \%)$ that provides the density of surface states steepening CVC characteristics as well as increased $\mathrm{pH}$ sensitivity sensors based on ISFETs; 5) high thermal stability and 6) high-quality immobilization of biochemical elements at the creation of biosensors.

In sensor devices the dielectric layers deposited on semiconductor have as passive role and serve as chemical sensitive membrane. This imposes rather stringent conditions on their quality (thickness and uniformity), considering that the area of contact with the electrolyte can be relatively large (from 0.1 to tens of $\mathrm{mm}^{2}$ ).

This work was devoted development of the immune biosensor based on $\mathrm{CeO}_{x}$ and studying of its analytical characteristics at the determination of content in model solutions such toxic substances as mycotoxin $\mathrm{T} 2$ and simazine.

The problem of dispersion of mycotoxins among of environmental objects is very important due to their external toxicity, especially, it concerns T2-micotoxin and pesticides. Biosensors are the most appropriate instrumental analytical devices which may fulfill all practice demands. Among them a lot of different types are exist and there is necessary to chose the most sensitive, stable and simple which may provide analysis in on line regime and in field conditions. Immune biosensors based on the ISFETs may respond these demands. Unfortunately, the stability and sensitivity of $\mathrm{SiO}_{2}-\mathrm{Si}_{3} \mathrm{~N}_{4}$-layer in the commonly used ISFETs is not sufficient and to overcome this shortcoming we created semiconductor structure with the $\mathrm{SiO}_{2}-\mathrm{CeO}_{2}$-layer.

\section{Experimental.}

The technology of ISFETs creation is the same as the preparation of metal-dielectric-semiconductor structures. As external shutter it was used $\mathrm{CeO}_{x}$ layer of which was fabricated by method of "oxidization of metallic mirror" at which firstly thin $\mathrm{CeO}_{2}$ layers were formed by electron beam evaporation. This technology can be done with using of standard equipments and relative low temperature. It does not demand a lot of time and is quite simple. The chamber pressure was $10^{-5} \mathrm{~Pa}$, the emission current was equal to $140 \mathrm{~mA}$, accelerating voltage $-12 \mathrm{kV}$, substrate temperature was in the range $170 \div 180{ }^{\circ} \mathrm{C}$.

After the deposition the substrate was maintained at this temperature for 10 minutes. Oxidation of cerium was carried out in a diffusion furnace at $250{ }^{\circ} \mathrm{C}$ in oxygen. We investigated the ISFETs with two types of insulators: $\mathrm{SiO}_{2}-\mathrm{Si}_{3} \mathrm{~N}_{4}, \mathrm{~d}_{\mathrm{Si} 3 \mathrm{~N} 4}=50 \mathrm{~nm}$ and $\mathrm{CeO}_{2} \mathrm{~d}_{\mathrm{CeO} 2}=50 \mathrm{~nm}$. The measurements were performed at room temperature and atmospheric pressure. To measure the $\mathrm{pH}$ sensitivity using standard buffer solutions with $\mathrm{pH}: 12.45 ; 9.18 ; 6.86 ; 4.01 ; 3.56 ; 1.68$.

The design parameters of ISFETs were studied by methods of optical and scanning microscopy. The cut crystals of ISFETs in the field of the gate in the direction transverse to the diffusion region are shown in Fig.1. The parameters of dielectric layers were made by scanning microscopy (Fig. 2).

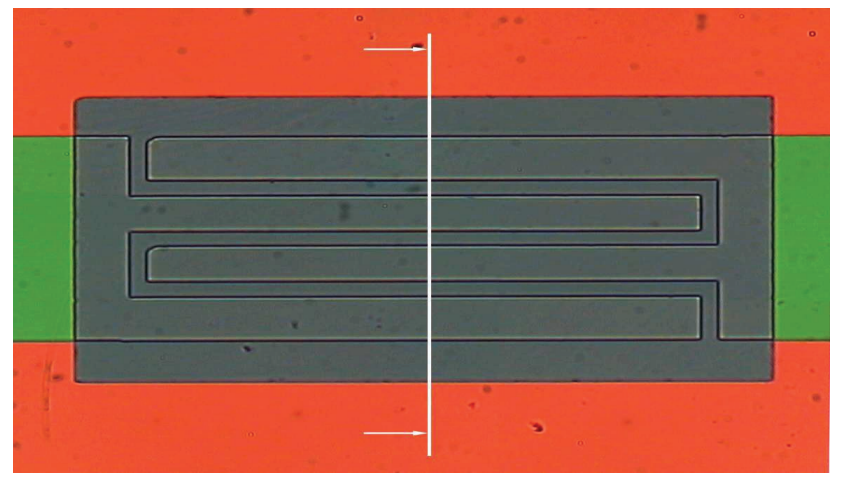

Fig. 1. Picture of the ISFET gate with the indicating the location of the cut.

Immune biosensor was created by the next way. It was used the differential scheme of measurements when the reference ISFET was covered by bovine serum albumin and working one - by the specific $A b$ through the intermediate layer from the staphylococcal protein A. Analysis was fulfilled in 
two way: competitive and so called "to saturation". In first one simazine or mycotoxin T2 labeled by horse radish peroxidase (HRP) competed with that which should be analyzed. In second one at first the immobilized $\mathrm{Ab}$ interacted with simazina or mycotoxin $\mathrm{T} 2$ in the sample and then with the solution of this analyte but labeled by HRP. The activity of HRP was registered in the presence of the special working buffer containing $5 \mathrm{mM}$ tris- $\mathrm{HCl}(\mathrm{pH} 7.5), 100 \mathrm{mM} \mathrm{NaCl}, 15 \mathrm{mM}$ ascorbic acid and 5 or $10 \mathrm{mM} \mathrm{H}_{2} \mathrm{O}_{2}$. The substrate conversion causes a local basic $\mathrm{pH}$ shift, because dehydroascorbic acid formed is a more neutral compound compared to ascorbic acid. The signals $(d V / d t)$ of the ISFETs were registered by electronic device providing signal amplification and its processing on the basis of a custom-made computer program. After every assay the chip was treated 5 min by $0.1 \mathrm{M} \mathrm{HCl}$ and then it was carefully washed with the above mentioned tris- $\mathrm{HCl}$ buffer.

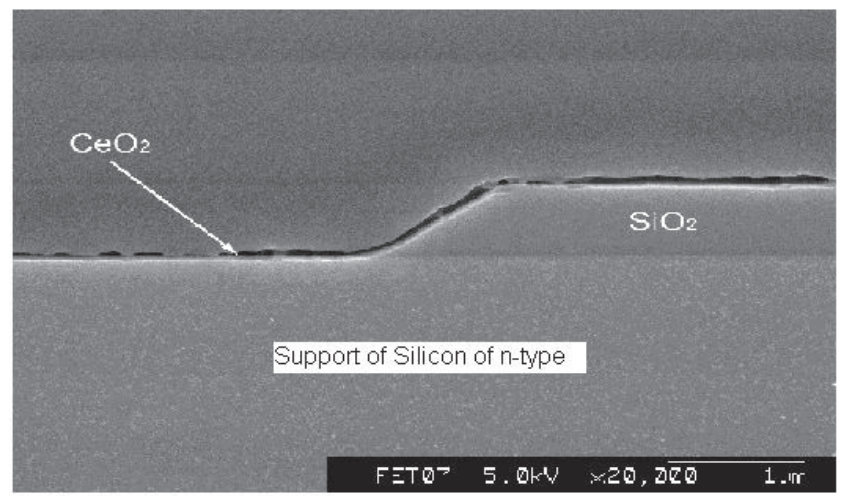

Fig. 2. Scanning electron microscopy of ISFET gate surface.

\section{Results and discussin.}

Any surface oxide always contains hydroxyl groups. In case of $\mathrm{CeO}_{x}$ the changes of surface charge at the variation of $\mathrm{pH}$ arise due to $\mathrm{CeOH}$ groups. Between protons in solution and hydroxyl groups formed on the boundary of $\mathrm{CeO}_{2}$-solution the equilibrium reactions have place. The hydrogen proton concentration may be determined according to shift of the threshold voltage of ISFET or to change the drain current in the transistor channel. The experimental characteristics of the studied ISFETs are presented in Fig. 3.

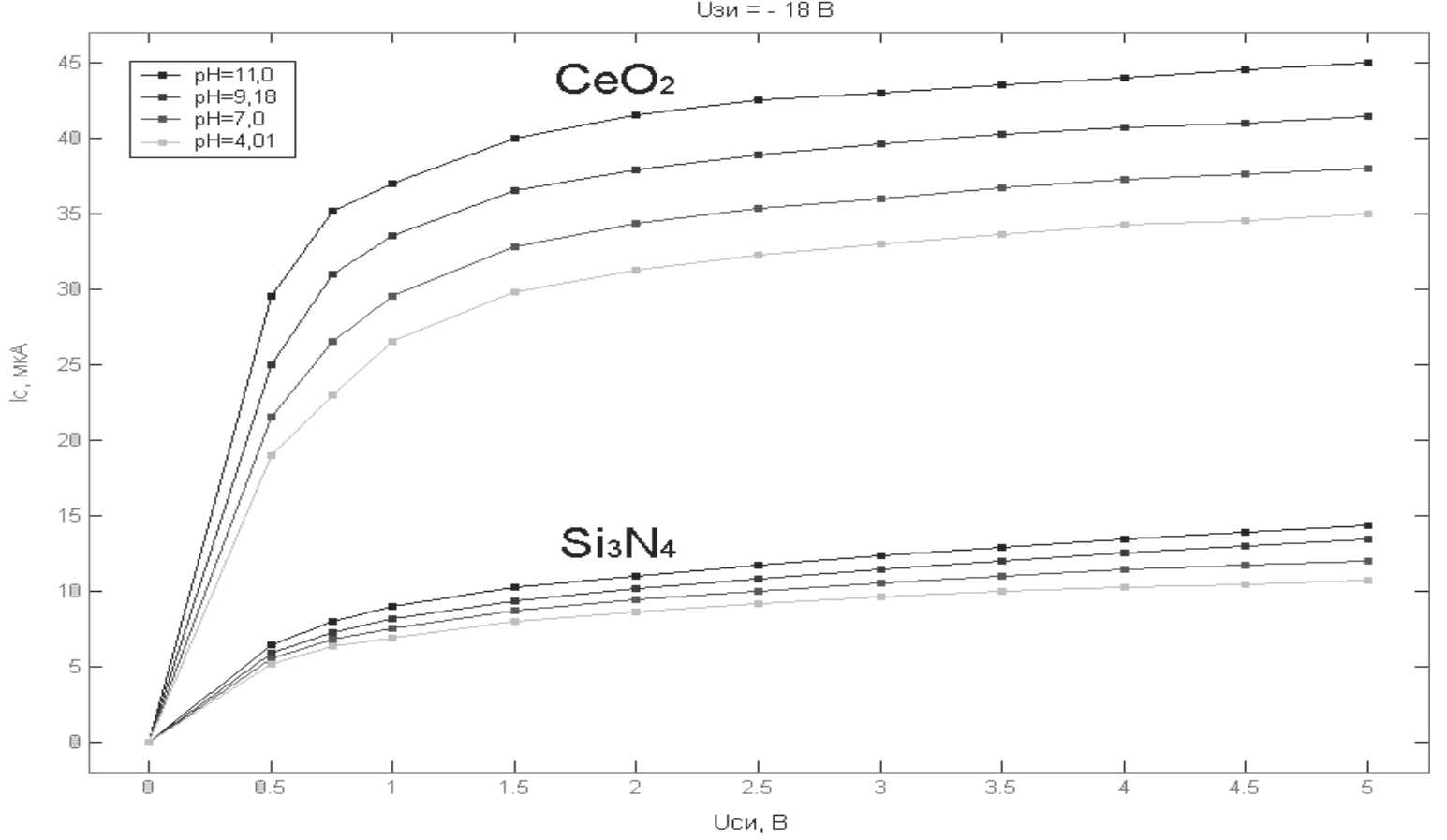

Fig. 3. Influence of $\mathrm{pH}$ on the output characteristics of ISFETs with the $\mathrm{Si}_{3} \mathrm{~N}_{4}$ and $\mathrm{CeO}_{2}$ dielectric structures.

At the $\mathrm{pH}$ increasing of solution the value of positive charge on the surface of ion-sensitive dielectric is decreased. Since we used $p$-channel ISFETs the decreasing of positive charge on the dielectric surface leads to increasing in channel conductance and hence to increase the drain current for both structures $\mathrm{SiO}_{2}-\mathrm{Si}_{3} \mathrm{~N}_{4}$ and $\mathrm{SiO}_{2}-\mathrm{CeO}_{2}$. According to our investigations the most linear and stable 
responses for both dielectric structures were registered at the voltage in $10 \mathrm{~V}$. The same they had linear character of dependence on $\mathrm{pH}$ changes. $\mathrm{pH}$ sensitivity for $\mathrm{SiO}_{2}-\mathrm{Si}_{3} \mathrm{~N}_{4}$ was $63 \mathrm{mV} / \mathrm{pH}$ and for $\mathrm{CeO}_{2}-58$ $\mathrm{mV} / \mathrm{pH}$ that is very close to the maximal possible sensitivity, so called Nernst sensitivity, which according to theory binding centers in case semiconductor-dielectric-solution may achieve $53 \mathrm{mV} / \mathrm{pH}$. The sensitivity of current flow due to the large dielectric constant of cerium oxide was increased more than two times $(\varepsilon=26)$.

The characteristics of immune biosensor were started with determination of some initial parameters.

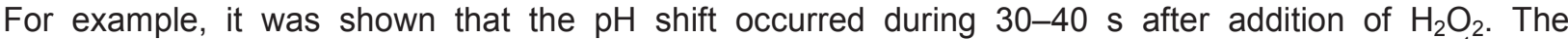
concentrations of the HRP-simazine or T2 conjugates were varied in the range $0.05-0.4 \mu \mathrm{g} \mathrm{ml}^{-1}$ and it was found that the maximal sensor output (about $100 \mathrm{mV}$ ) corresponded to $0.1 \mathrm{\mu g} \mathrm{ml}^{-1}$ of the conjugate. Under these conditions binding sites of the specific Ab were saturated. That is why the concentration of the above mentioned HRP-labeled substances during the competitive analysis was equal to $0.1 \mu \mathrm{g} \mathrm{ml}^{-1}$. Reliable decrease of the sensor signal was observed down to 1.0 and $3.0 \mathrm{ng} \mathrm{ml}^{-1}$ of simazine and T2 mycotoxin in the analyzed mixture, accordingly. The linearity of signal decrease was observed in the range of T2 mycotoxin concentrations from 5 to $190 \mathrm{ng} \mathrm{ml}^{-1}$ (Fig. 6, 7). In this range the potential of the IsFET gate varied from 95 to $5 \mathrm{mV}$. The similar situation was occurred in case of simazine (2-150 $\left.\mathrm{ngml}^{-1}\right)$. In both cases the standard deviation was on average about $5 \%$. The overall time of the assay including the duration of all preparation stages was $30 \mathrm{~min}$. The limiting stage of the analysis is the competition between the labeled and native substances for binding with $\mathrm{Ab}$ (up to $10 \mathrm{~min}$ ). In case of the analysis by "to saturated way" allowed reaching sensitivity $0.5 \mathrm{ng} \mathrm{ml}^{-1}$ and linearity in the range 1.0-200 $\mathrm{ng} \mathrm{ml}^{-1}$ and 0.5-170 for T2 mycotoxin and simazine, respectively (Fig. 8, 9). The overall time of the incubations was the same $10 \mathrm{~min}$ ( $5 \mathrm{~min}$ for the staying chip in the solution of the native and the labeled substances).

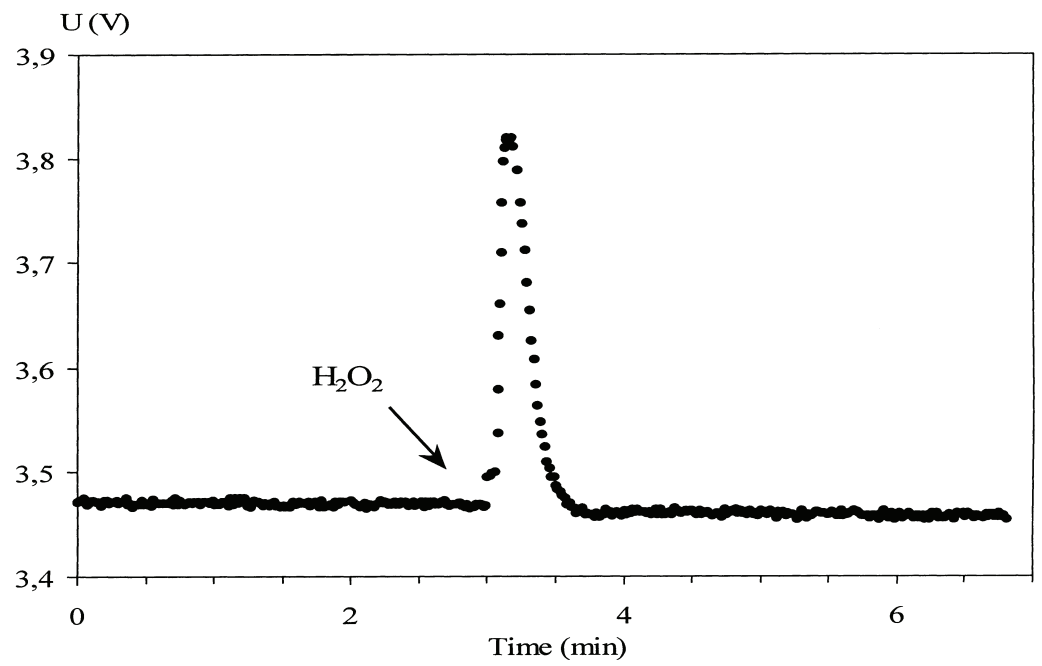

Fig. 4. Typical response of the sensor at the addition of $\mathrm{H}_{2} \mathrm{O}_{2}$. The ISFET potential is recorded as a function of time.

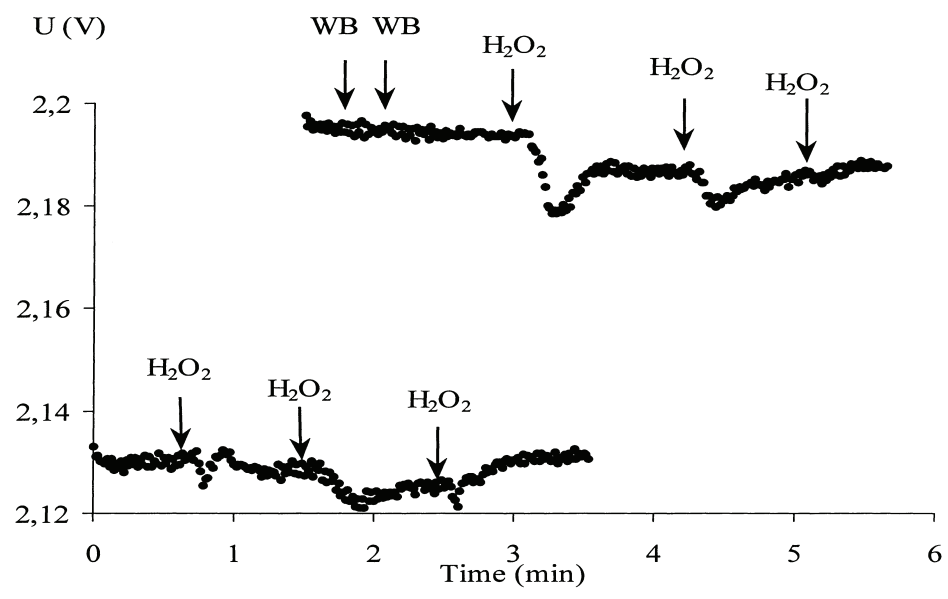

Fig. 5. Non-specific sensor response at the addition of $\mathrm{H}_{2} \mathrm{O}_{2}$ and buffer. The ISFET potential is recorded as a function of time. 


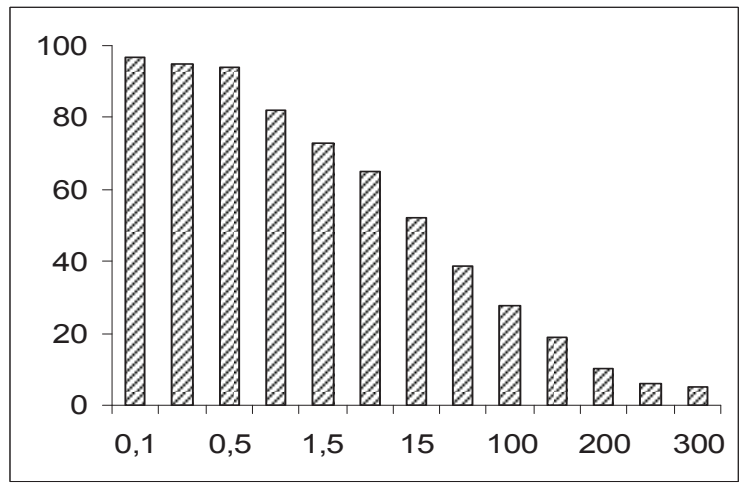

Fig. 6. Determination of T2 mycotoxin in solution with the help of the cerium oxide ISFET biosensor by the "competitive" way of analysis. Ordinate $-\mathrm{mV}$, Abscises $-\mathrm{ng} / \mathrm{ml}$.

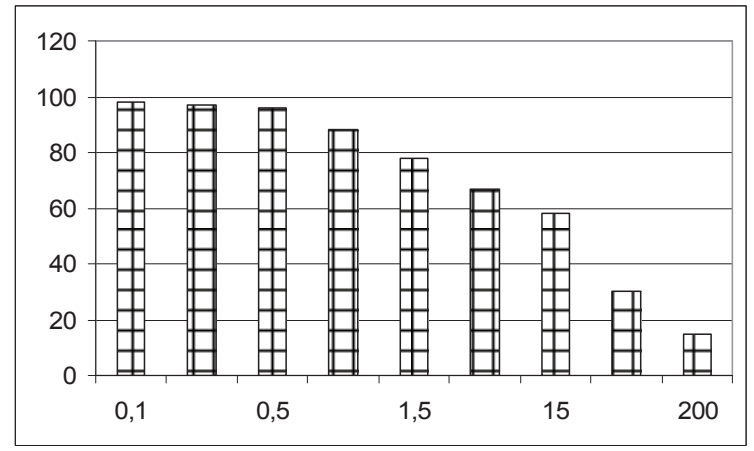

Fig. 7. Determination of simazine in solution with the help of the cerium oxide ISFET biosensor by the "competitive" way of analysis.. Ordinate $-\mathrm{mV}$, Abscises $-\mathrm{ng} / \mathrm{ml}$.

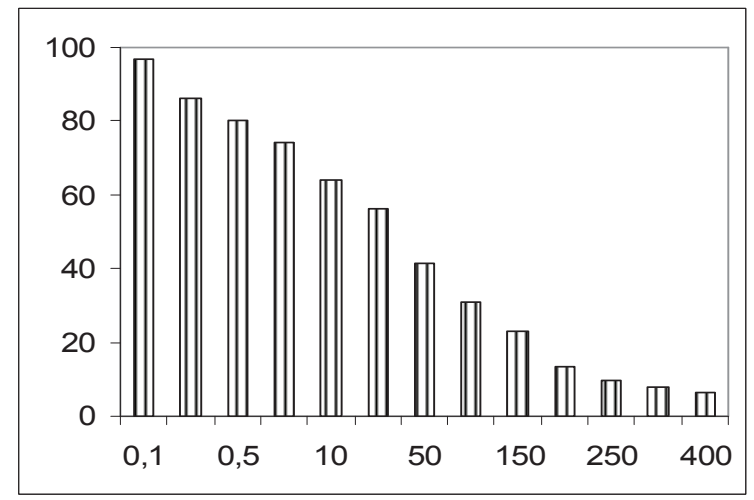

Fig. 8. Determination of T2 mycotoxin in solution with the help of the cerium oxide ISFET biosensor by the "to saturation" way of analysis. Ordinate - $\mathrm{mV}$, Abscises - ng/ml.

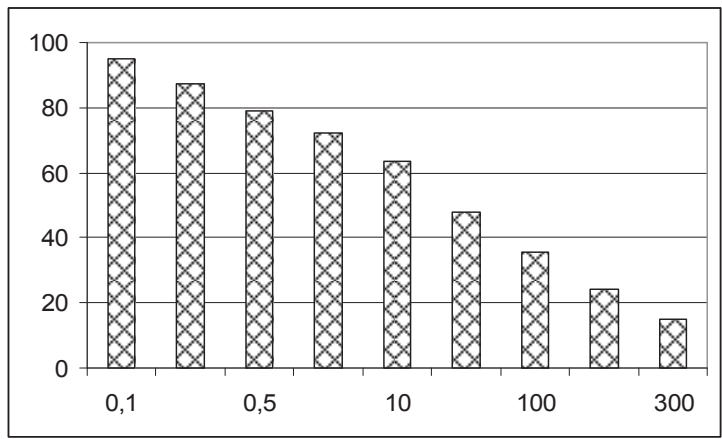

Fig. 9. Determination of simazine in solution with the help of the cerium oxide ISFET biosensor by the "to saturation" way of analysis. Ordinate $-\mathrm{mV}$, Abscises $-\mathrm{ng} / \mathrm{ml}$. 
The developed immune biosensor based on the CeOx IsFETs shown much more high sensitivity of T2 mycotoxin determination (up to 2 orders) than that which is based on the SPR [2, 3].

The sensitivity of the developed immune biosensor is approximately to that which was revealed in similar biosensor based on the total internal reflection ellipsometry [4]. Moreover, the IsFETs based immune biosensor may be simple used a several times after the destruction of the formed immune complex by the treatment of chips with $0.1 \mathrm{M} \mathrm{HCl}$ for 5 min and than by washing of tris- $\mathrm{HCl}$ buffer $(5 \mathrm{mM}$, $\mathrm{pH}$ 7.5). Such procedure may be realized too in case of the SPR based immune biosensor but it is more complicate. The mentioned advantages of the immune biosensor based on the IsFET are very important for practice when it is necessary to fulfill the simple, fast and very sensitive analysis in field conditions. The similar immune biosensor based on the ISFETs was developed by us for the determination of the herbicide simazine [5]. It was constructed on the chip surface of which was covered by $\mathrm{Si}_{3} \mathrm{~N}_{4}$. $\mathrm{Since}$, the principle of the immune analysis was the same it is possible to compare the sensitivity and the stability of the biosensors based on the silicon nitride and cerium oxide ISFETs. Both parameters are much better for last ones. For example, CeOx IsFETs may be reused in 4 times longer and it sensitivity in 10 and more times higher than that which has $\mathrm{S}_{3} \mathrm{~N}_{4}$-layer.

\section{Conclusion}

It was created immune biosensors based on the CeOx ISFETs which may recommended for practice application due to its high sensitivity, stability and simplicity of use for express determination of mycotoxins among environmental objects, especially, in corn. This sensor is corresponding to all practice demands. Certainly, for practical application there is necessary to develop a special method for obtaining of extracts from sample to be analyzed, in particular from that which are presented solid phases. In previous experiments [6-9] we demonstrated that acetonitrile and methanol are as most appropriate solvents in this case. Moreover, it was shown that first of them may be used in final concentration about $30 \%$ during immune biosensor analysis. Methanol should be used in a few small concentrations (about $20 \%$ ). Obtained experimental results about sensitivity of the immune biosensor based on the $\mathrm{CeO}_{x}$ ISFETs as well as information about ways of sample preparation testify perspective of these approaches for practice application.

\section{References}

1. Shmyryva O. M., Rodak D. O. High sensitive microelectrinic sensor for pH determination. Scientific News, 2007, N 4, pp. 32-38.

2. Starodub N. F., Pilipeko L. N., Pilipenko I. V., Egorova A. V. Mycotoxins and other low weight toxins as instrument of bioterrorists: express instrumental control and some ways to decontaminate polluted environmental objects. Timisoara Medical J., 2008, v. 58, no. 1-2, pp. 9-18.

3. Starodub N. F. Biosensors in the system of express control of chemicals, regularly used as terrorist means to prevent non-desirable consequences. In: The role of Ecol Chem in Pollution Res and Sustainable Develop. Ed. Ali M. Bahadir and G. Duca. Springer Sci+Business Media BV, 2009, pp. 275-384.

4. Nabok A.V., Tsargorodskaya A., Holloway A., Starodub N. F., Gojster O. Registration of T2 mycotoxin with total internal reflection ellipsometry and QCM impedance methods. Biosensors and Bioelectronics, 2007, v. 22, pp. 885-890.

5. Starodub N. F., Dzantiev B. B., Starodub V. M., Zherdev A.V. Immunosensor for the determination of the herbicide simazine based on an ion-selective field-effect transistor. Anal. Chim. Acta, 2000, v. 424, pp.37-43.

6. Starodub N.F., Shulyak L.M., Shmyryeva O.M., Pylipenko I.V., Pylipenko L.N., Mel'nichenko M.M. Nanostructured Silicon and Its Application as the Transducer in Immune Biosensors. In: Proc. NATO Sci. for Peace "Biodefence: Materials and Methods for Health Protection". Chapter II "Methods of Detection and Analysis", Springer, 2010, pp. 216-223.

7. Starodub N. F. Development and application of the optical and electrochemical biosensors for the express screening of water and food quality. Technical Digest of 13th International Meeting on Chemical Sensors. University of Western Australia, Perth Western Australia Sunday 11th - Wednesday 14h July 2010, p. 49.

8. Pylypenko I. V., Pylypenko L. N., Starodub N. F., Brezvin O. M. Biosensors at the determination of mycotoxins. In: Abstract book of 4-th Intern. Conf. "Sensor electronics and microsystem technologies" (SEMESR-4), 28june02 July 2010, Odessa, p. 227.

9. Starodub N. F. Biosensors for determination of mycotoxins: development, efficiency at the analysis of model samples and in case of practical applications. Book Abstracts in: $107^{\text {th }}$ International Center of Biocybernetics Seminar "Micro and Nanosystems in Biochemical Diagnosis - Principles and Applications", Warsaw 13 - 15 May 2010, p. 24-25. 